\title{
A CASE STUDY EXAMINING THE COST MEASUREMENTS IN PRODUCTION AND DELIVERY OF A SMALL PRIVATE ONLINE COURSE (SPOC) FOR TEACHING ADMINISTRATIVE STAFF TO ENGAGE WITH YOUNG PATIENTS
}

\author{
E. Meinert \\ University of Oxford (UNITED KINGDOM) \\ J. Eerens \\ Imperial College London (UNITED KINGDOM) \\ C. Banks \\ Imperial College London (UNITED KINGDOM) \\ J. Car \\ Imperial College London (UNITED KINGDOM)
}

\begin{abstract}
Background

eLearning (defined as asynchronous/synchronous online learning delivered via the internet, either used on a stand-alone basis or using blended learning design) presents a significant opportunity to provide a scalable and cost-effective means of delivering of health education in contrast to one-time delivery of face to face instruction. Economic evaluation makes use of implementation costs for the basis of comparative analysis of cost value determination between different intervention types. Although there exist models for the calculation of costs in standard education programmes, eLearning is a different implementation design than face to face instruction because the initial effort is concentrated on the construction of intervention before implementation and the factors which influence their production require iteration and refinement. Understanding these iterations and their impact on cost is vital in order to develop a strong evidence base on the total cost of implementation of eLearning.
\end{abstract}

\section{Objective}

To identify the ingredients for the production and delivery of a small private online course, complete a variance calculation of the ingredients for the cost of production and delivery of a small private online course and explore the factors impacting the planning of costs for eLearning delivery.

\section{Methods}

This study uses a mixed-methods study design was implemented, with a single-use case study design structured for study observation and cost analysis used to analyse financial data.

Results

The implementation costs of the course were significantly underestimated at commencement making the total effort to deliver the cost untenable when baselined against the budget with a $41 \%$ negative variance from the project budget. The course was delivered despite this budget overrun because there was an obligation to deliver the course for the anticipated budget; had they failed to do this they would not have received compensation from the funder for the course activity. The two principal factors for the cost overruns were the deficiency of the use of the project budget and the under-reporting of personnel costs. 


\section{Conclusions}

Although there has been the development of costing capture models for the capture of the components or ingredients of educational interventions, the driver for these models has been the development of frameworks to allow for the further economic evaluation of learning types. Further work is required to the foundational aspects of cost capture in the production of eLearning, as to ensure that total costs are recorded to capture the real costs of delivery.

Keywords: Education (MeSH); Education, Distance (MeSH); Education, Professional (MeSH); Online Education; Online Learning; Costs and Cost Analysis (MeSH); Economics (MeSH)

\section{INTRODUCTION}

The World Health Organisation (WHO) World Health Report [1] suggests that there is a significant need to increase global healthcare resourcing in order to meet present and future demand. eLearning (defined as asynchronous/synchronous online learning delivered via the internet) presents a significant opportunity to provide a scalable and cost-effective means of delivering of health education in contrast to one-time delivery of face to face instruction [2]. In order to realise these cost savings, economic evaluation provides the opportunity to explore where there are advantages for the implementation of eLearning versus traditional means and the factors that drive their optimisation or inefficiencies [3]. Economic evaluation makes use of implementation costs for the basis of comparative analysis of cost value determination between different intervention types [4]. Although there exist models for the calculation of costs in standard education programmes, eLearning is a different implementation design than face to face instruction because the initial effort is concentrated on the construction of an intervention before implementation and the factors which influence their production require iteration and refinement [5]. Understanding these iterations and their impact on cost is vital in order to develop a strong evidence base on the total cost of implementation of eLearning.

Small private online courses (SPOC)s are a form of eLearning derived from Massive Open Online Courses (MOOC)s which are targeted for specific learner groups [6]; they can be distributed at scale, but unlike MOOCs which are intended for a large and unstructured aggregate audience, SPOCs are focused on specific learners for review and learning of their learning content.

\section{Case description}

The Child and Young People's Health Partnership (CYPHP) was formed as a large-scale initiative to improve the quality of care and physical and mental wellbeing of children and young people in the diverse London boroughs of Lambeth and Southwark. Following the development of a needs assessment and youth panel report detailing the situation regarding young people's health, the work identified barriers to young people seeking help from their GP for health services including mental health due to fears over confidentiality and services not being young friendly. This investigation recommended that workforce training be carried out for both clinical and non-clinical staff can effectively respond to the health needs of adolescents. This work identified a need for educating general practice office staff on handling adolescents and adolescent matters at the surgeries has been identified. The purpose of this project was to implement a small private online course that would be used by receptionist and administrative staff $(n=187)$ to learn these critical skills. The course was implemented by an eLearning production team at the Imperial College London eHealth Unit, funded by the European Institute of Innovation and Technology - Health KIC as an education grant for the production of digital learning.

The course taught receptionists and administrative staff about the legal and medical confidentiality status of adolescents at different ages and use case studies to increase knowledge and confidence in handling different types of situations. By addressing this gap in knowledge and experience, it is hoped that this course will improve the experience of young people when using general practice and therefore improve their attendance which is crucial during adolescence. The course was developed and built from November 2015 through August 2016 and delivered to participants from September 2016 - December 2016. 
The purpose of this study was to determine how the total costs for the production and delivery of a SPOC are calculated, within the context of the delivery of a health-centred training course.

\section{Objectives}

1. Identification of the components or "ingredients" for the production and delivery of a small private online course

2. The utilisation of a variance calculation of the ingredients for the cost of production and delivery of a small private online course

3. Explore the factors impacting the planning of costs for eLearning delivery

\section{METHODOLOGY}

The study involved the determination of the costs associated with the production of a small private online course. A mixed-methods study design was implemented, with a single-use case study design structured for study observation and cost analysis used to analyse financial data. Ethical approval for the study was obtained through the Imperial College Education Ethics Research Committee (EERP1516-005).

\section{Methodologic framework}

A case study research design was selected because the investigation was centred on decisions which would not be subject to experimental variables of the stakeholders delivering the project or the participants taking part in the course; the study strictly focused on the financial decisions of the course designers. This "real-world" analysis of cost accounting of a small private online course provides primary evidence on issues and implications in budgeting and course production and delivery.

This investigation followed a systematic six-stage approach [7] to identify the costs associated with the production of a small private online course.

\section{Stage 1: Plan}

We considered the study design to validate the appropriate method for the investigation. Because the study was centred on an implementation of an online course which would not be subject to experimental variables on the stakeholders, a case study method was deemed most appropriate.

The research question centred on capturing the total costs for the production and delivery of the course. This research question was selected because evidence from the literature suggests there is inconsistency in the determination of costs for the delivery of online courses [8]. This is significant because of this lack of consistent cost capture mechanisms for the production of online learning any further economic evaluation is compromised. Despite methods to avoid this outcome, the literature presents research with such deficiencies and claims that online learning is "cost effective" in comparison to face to face learning. This case was planned to explore why and how this occurs.

\section{Stage 2: Design}

The research design was structured on four components (proposition, the case (definition), logic linking data to the proposition, criteria for interpreting findings) to explore the research question: How are the total costs for the production and delivery of a small private online course calculated? Given inconsistency in the presentation of costs from literature and recognising that using budgets as means of determining the cost of educational delivery are insufficient [4], the governing proposition of the investigation was that there would be a variance between the budgeted costs and the actual costs to produce the course. This was explored through the case which would examine the cost and measurement of costs and placing value on ingredients. This "ingredients method" was developed by 
Levin to capture and analyse the costs in the delivery of an educational programme. In order to link the case to the proposition cost analysis was completed and then interpreted via a variance calculation of actual to budgeted costs and rationale developed to justify variations.

Table 1: Case study research

\begin{tabular}{|l|l|l|l|l|}
\hline \multicolumn{1}{|c|}{ Study question } & \multicolumn{1}{|c|}{ Proposition } & $\begin{array}{l}\text { The case } \\
\text { (definition) }\end{array}$ & $\begin{array}{l}\text { Logic linking data } \\
\text { to the proposition }\end{array}$ & $\begin{array}{c}\text { Criteria for } \\
\text { interpreting } \\
\text { findings }\end{array}$ \\
\hline $\begin{array}{l}\text { How are the total costs } \\
\text { for the production and } \\
\text { delivery of a small } \\
\text { private online course } \\
\text { calculated? }\end{array}$ & $\begin{array}{l}\text { Actual costs and } \\
\text { budgeted costs will } \\
\text { vary in the } \\
\text { production/delivery } \\
\text { of this course type }\end{array}$ & $\begin{array}{l}\text { Determination } \\
\text { and } \\
\text { measurement } \\
\text { costs }\end{array}$ & $\begin{array}{l}\text { Cost analysis of } \\
\text { project costs, } \\
\text { actual cost and } \\
\text { underreported } \\
\text { costs }\end{array}$ & $\begin{array}{l}\text { Variance } \\
\text { calculation } \\
\text { the project budget }\end{array}$ \\
\hline
\end{tabular}

In order to validate the research design, three tests [7] were used to assure quality in the case design.

Table 2: Research design tests (Adopted from [6])

\begin{tabular}{|l|l|}
\hline Test & Description \\
\hline Construct validity & $\begin{array}{l}\text { The purpose of a construct validity test is to demonstrate that data sources } \\
\text { are triangulated from multiple sources [7]. }\end{array}$ \\
\hline External validity & $\begin{array}{l}\text { The purpose of an external validity test is to demonstrate how principal } \\
\text { findings could be extensible [7]. }\end{array}$ \\
\hline Reliability & $\begin{array}{l}\text { The purpose of the reliability test is to show how the activities of the study } \\
\text { can be replicated [7]. }\end{array}$ \\
\hline
\end{tabular}

\section{Stage 3: Prepare}

A study protocol was created (Appendix A) to prepare the procedure for data collection. The study protocol provided a framework for the overall study execution and details for the means of analysis for the research question. The investigation was focused on cost measurement and analysis, structured by three cost categories and further sub-divided using a 12-step process to analyse the pre-production and post-production budget [4]. Levin's model uses an activity-based costing standard costing accountancy approach, which assigns costs as they are consumed per implementation area [9-11].

Table 3: Course production ingredients cost analysis, adapted from Levin [4]

\begin{tabular}{|c|r|}
\hline Cost Categories & Objectives \\
\hline A. Concept and measurement of & 1. $\begin{array}{l}\text { Describe the concept of costs } \\
\text { costs }\end{array}$ \\
& $\begin{array}{l}\text { 2. } \begin{array}{l}\text { Show the inadequacy of } \\
\text { budgets for cost analysis } \\
\end{array} \\
\text { 3. Present a methodology for } \\
\text { measuring costs }\end{array}$ \\
\hline
\end{tabular}




\begin{tabular}{|c|c|}
\hline & 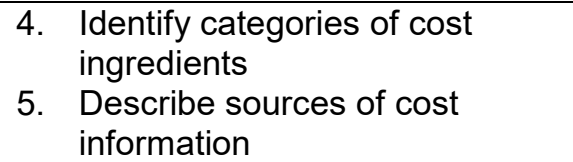 \\
\hline B. Placing values on ingredients & $\begin{array}{l}\text { 6. Describe the purpose and } \\
\text { principles for determining the } \\
\text { values of ingredients } \\
\text { 7. Present methods for placing } \\
\text { values on specific types of } \\
\text { ingredients } \\
\end{array}$ \\
\hline C. Analysing costs & $\begin{array}{l}\text { 8. Summarise the application of } \\
\text { cost methodology with the use } \\
\text { of a cost worksheet } \\
\text { 9. Show how to analyse the } \\
\text { distribution of cost burdens } \\
\text { among different stakeholders } \\
\text { 10. Address cost estimation for } \\
\text { multi-year projects } \\
\text { 11. Illustrate the estimation of costs } \\
\text { under uncertainty } \\
\text { 12. Present different ways of using } \\
\text { costs for decisions }\end{array}$ \\
\hline
\end{tabular}

\section{Stage 4: Collect}

\section{Data collection}

Evidence from the course was retrieved from project documents and records of finance activity. The data collection strategy was executed from a realist perspective to capture the decisions made by the course designers, however, did not incorporate a relativist perspective as to the distinct perspectives of the stakeholders through further qualitative investigation. This decision was made to avoid interference in the delivery of the course. In order to control biased selectivity and reporting bias, data was triangulated through multiple sources, including finance logs (and notes), data submitted to the employer, the funder and timesheets. A traceability log was maintained linking the study questions to the relevant data sources and the study findings.

\section{Stage 5: Analyse}

Data analysis centred on the three cost categories and followed the 12-step process for cost definition.

\section{Category A: Concept and measurement of costs}

The pre-production budget was analysed for the following ingredient categories: 1) personnel, 2) estate charges, 3) equipment and materials, 4) indirect costs and 5) stakeholder costs. The initial budget did not reflect time for stakeholder costs (effort from third-party lecturers), so this was captured as the additional time that was monitored in the study as there was no value for this in the data that was submitted to the funder.

\section{Category B: Placing values on ingredients}

With the full cost of production defined, values were associated with each ingredient sub-category to reflect the chargeable cost.

\section{Category C: Analysing costs}

Because the course was implemented in one year and an online course, there was no multi-year costs to calculate; the one-time cost of the project and the variance of the projected budget to the actual budget was the only variable under consideration. To accomplish this, a variance calculation of the 
budget to the incurred costs was completed at the completion of the project. The variance calculation is an approach where actual spend is compared to adjusted standard conditions based on what occurred [12].

Variance $=$ Actual spending - Budgeted spending

\section{Stage 6: Share}

The findings of the variance calculation and analysis of reasons leading to variation were presented in a case report to the course design team. Feedback was gathered on analysis and results; the key findings for this report were prepared for publication (this manuscript). 


\section{RESULTS}

\section{Course production costs}

Category A: Concept and measurement of costs

Table 3: Ingredient categories

\begin{tabular}{|l|l|}
\hline Ingredient categories & Cost components \\
\hline Personnel & University staff \\
\hline Estate charges & IT services charges \\
\hline Equipment and materials & $\begin{array}{l}\text { Course production equipment, application development costs for the } \\
\text { creation of software to support the MOOC }\end{array}$ \\
\hline Indirect costs & University overheads \\
\hline Stakeholder costs & Staff for third-party subject matter consultancy \\
\hline
\end{tabular}

Category B: Placing values on ingredients

Upon completion of the analysis of the ingredients of the course production, the initial budget was created and submitted to the funder.

Table 4: Ingredient Costs of the CYPHP SPOC

Cost in 2016

$\begin{array}{ll}\text { Personnel } & £ 71,119\end{array}$

Estate charges

Equipment and materials

$£ 16,773$

Indirect costs

$£ 22,717$

Stakeholder costs

$£ 9,823$

£129,382

Category C: Analysing costs 


\section{Budget variance calculation}

The Actual spend varied from budgeted spend in Personnel, Equipment and materials and Stakeholder costs. The only reason that this variance was captured was because of the comparison of the timesheet hours and the variance from planned spend; had it not been for the recording of this information this data would have been lost because the only reported information to the project funder was the initial budget (as this was the amount seeking reimbursement.

The most significant variance was in equipment and materials, primarily from the costs of application development in the creation of a custom online course. As the production team had not done this before, there was a significant underestimate of the amount of time required to build and configure the system (which was developed using the Open edX platform) and course editing. Additionally, specialist recording equipment had to be procured that was not understood at the time of budget completion.

The next most substantial variance was the amount of time required from third party stakeholders in the production of the learning materials. This included the course lecturers from the CYPHP programme. The amount of time allocated for recording the lecturers was underestimated as once the initial recordings were completed, there had to be several re-runs of the recordings to address content changes.

The last cost variance was in the personnel costs to deliver the course. While the variance was the smallest of the three categories, this variance was significant because the course production team did not receive any additional compensation for their additional work; this extra work was captured in the project timesheets but not submitted to the funder for reimbursement.

Table 5: Ingredient Costs variance calculation

\begin{tabular}{|c|c|c|c|c|}
\hline & Budget & Actual & Variance & $\begin{array}{l}\text { Var } \\
\%\end{array}$ \\
\hline Personnel & $f 71,119$ & $f 93,455$ & $f 22,336$ & $31 \%$ \\
\hline Estate charges & $£ 8,949$ & $f 8,949$ & f0 & $0 \%$ \\
\hline Equipment and materials & $£ 16,773$ & $£ 39,455$ & $£ 22,682$ & $135 \%$ \\
\hline Indirect costs & $£ 22,717$ & $£ 22,717$ & f0 & $0 \%$ \\
\hline Stakeholder costs & $£ 9,823$ & $£ 17,333$ & $£ 7,510$ & $76 \%$ \\
\hline & $£ 129,382$ & $f 181,910$ & $£ 52,527$ & $41 \%$ \\
\hline
\end{tabular}

The construction of the cost ingredients and subsequent cost analysis underwent three validation tests: 
A. Construct validity test: To achieve data triangulation, the case study had multiple sources of cost data. The project budget which was submitted to the 1) project funder, 2) the actual costs submitted to the funder at the completion of the project and 3) the timesheet log of hours captured by the course implementers. The final case report was reviewed, and feedback gathered from the course designers (BS, MT); any inconsistencies or inaccuracies were corrected.

B. External validity test: By using Levin's ingredients method for cost identification, the case followed an established costing procedure which is used as the basis for analytic frameworks for economic evaluation in education. This process based on a common analytic framework allows for the generalisation of the study findings to similar use cases.

C. Reliability test: A study protocol was created at the commencement of the case; the protocol details the structure of the study and details how data was collected to ensure the reliability of the results. 
The course designers completed timesheets recording the construction of the course; this was structured by a detailed list of activities derived from a taskbased project plan. The course was structured into four modules, consisting of video recordings, worksheets and quizzes on the learning content.

Table 6: Summary of actions and schedule (Source: timesheets and project plan)

\begin{tabular}{|c|c|c|c|c|c|c|c|c|c|c|}
\hline \multirow{2}{*}{$\begin{array}{l}\text { Activity and Schedule } \\
\text { Recording/ Design/ Development / Production Team }\end{array}$} & \multicolumn{2}{|c|}{2015} & \multicolumn{8}{|c|}{2016} \\
\hline & Nov & Dec & Jan & Feb & Mar & Apr & May & June & Jul & Aug \\
\hline $\begin{array}{l}\text { Content Provider (1-day work for four lessons ( } x 7 \text { minutes video lecture per } \\
\text { total) }\end{array}$ & & & & & & & & & & \\
\hline Quizzes and questionnaires preparation & & & & & & & & & & \\
\hline Exercise ( 1 day to create exercises, one per Module) & & & & & & & & & & \\
\hline Instructional design (per $7 \mathrm{~m}$ of content) & & & & & & & & & & \\
\hline Text rework/ Story creation (per 7m video) & & & & & & & & & & \\
\hline Slide rework (number of slides from the original presentation) & & & & & & & & & & \\
\hline Intro's (video of prof introducing his course) & & & & & & & & & & \\
\hline Video production (per $7 \mathrm{~m}$ of content) & & & & & & & & & & \\
\hline Review by the lecturer (QA \& review: per 7m of content) & & & & & & & & & & \\
\hline Creation of supporting text per $7 \mathrm{~m}$ of video & & & & & & & & & & \\
\hline Creation of a glossary and reference for $7 \mathrm{~m}$ video & & & & & & & & & & \\
\hline
\end{tabular}


Video transcriptions (per $7 \mathrm{~m}$ of video)

Publication of video, text, quizzes and exercises

Creation of the texts which are sent to the learners

Creation of "About the Course" (FAQ, course surveys, instructors and tutors' text)

Development of custom-built online learning platform

\begin{tabular}{|l|l|l|l|l|l|l|l|l|l|}
\hline & & & & & & & & \\
\hline & & & & & & & & \\
\hline & & & & & & & & \\
\hline & & & & & & & & \\
\hline
\end{tabular}




\section{Participant information}

One hundred twenty-four learners enrolled in the SPOC from September to December 2016. Of the 124 learners, $84 \%$ completed the course and received a post-course certificate. The course uptake and completion, however, did not influence the production costs post-course implementation as the course was designed as a self-managed SPOC not requiring further administration post-deployment. 


\section{CONCLUSIONS}

Principal findings

The implementation costs of the course were significantly underestimated at commencement making the total effort to deliver the cost untenable when baselined against the budget. The course was delivered despite this budget overrun because there was an obligation by the university and the course team to deliver the course for the anticipated budget; had they failed to do this they would not have received compensation from the funder for the course activity. This dynamic creates a disincentive to report actual costs of projects and indicates that in this type of course delivery, where the effort is not as fixed as it would be in a face to face implementation of a course (where delivery costs are predicated on preparation and one-time delivery). This outcome would seem to indicate that the costs for the production of an online course are underreported. In reviewing the case results, two principal factors influenced the budget adherence to plan:

\section{The inadequacy of project budgets at the commencement of online learning for new teams}

As noted by Levin [4], project budgets are insufficient means of identifying the real costs of delivery of an educational course. The driver for this point is a recognition that budgets are often calculated without taking full consideration of the real costs of underlying variables that make up cost categories and an education ingredient-driven approach will, therefore, lead to more accurate costings. The critical challenge, however, is that even with a budget which was constructed using an ingredients method, the budget still proved insufficient because the real cost of the course had significant variation from an ingredients structured budget. The variability of actual to incurred spend, primarily for costs that are not reimbursed is a critical factor determining the true nature of spending for this type of learning.

\section{Underreporting of personnel costs}

Within the implementation context of a funded education grant, there is a disincentive to record actual time in the course delivery because there is a recognition that the additional cost will not be compensated. This additional effort produced by educators is not unique to eLearning production, but when examining the costs for the production of this learning type results in an underreporting of the real value of the cost associated with delivery. Software configuration, editing, online course construction and delivery via digital platform requires a logistic setup that is difficult to plan at onset, especially if the team delivering the work is working with new course content, which is often the case in the production of new materials.

\section{Strengths and limitations}

The strengths of this study are that it provided a rigorous case examination of the implementation of eLearning via a small private online course. The implementation context of teaching administrative health policy and patient considerations is an educational model that is topical and well-suited for online learning. The study was based on a systematic research design and implemented management accountancy methods which have been purpose-built for cost evaluation of learning. Data was validated to ensure tests of accuracy and the design of the methods of the course are repeatable and reproducible in this study context and within others.

There are two significant limitations to this study. The first is the possibility of bias within the financial data capture. Although the study triangulated data from multiple sources, it is possible that course designers did not report all costs. To mitigate this costing data was mitigated from different areas not directly from the course designers, but without direct observation of all activities, it is possible data could have been manipulated. A variance in the study design could have been embedding researchers within the project team to capture costing data instead of relying on data submitted from the course designers or university systems for time tracking. A second limitation of the study is it did not incorporate a further qualitative investigation of decisions by survey or interview of the course designers in order to conclude course impact. Incorporating such data could have provided further insight as to decision making. 


\section{Summary perspectives}

eLearning presents an opportunity to create scaled-up, multi-implementation construction of learning content which can then be distributed to enable access to a broad distribution of learners. The promise of such application within health professions education and the popularity of learning via mobile devices and via browsers has led to a significant expansion of such course deployments. There is a broad perception that the use of eLearning is more cost-effective than face to face instruction. When reviewing studies implementing eLearning there is a consistent reference to the cost-effectiveness or cost-benefits (Meinert 2019), however, due to a lack of standardisation in approach for the capture of costs, there is a need for further understanding of the relationship between costs and production of eLearning [13]. This case study explored the development of a small private online course for training administrative staff issues and considerations when working with young patients. The case demonstrated the real costs of implementation were beyond the initial budget leading to underreporting of costs; it is most likely when developing eLearning this is a consistent feature of projects due to the challenges of creating an online course which requires upfront effort and moderation before course delivery. Although there has been the development of costing capture models for the capture of the components or ingredients of educational interventions, the driver for these models has been the development of frameworks to allow for further economic evaluation of learning types. Further work is required to the foundational aspects of cost capture in the production of eLearning, as to ensure that total costs are recorded to capture the real costs of delivery.

\section{ACKNOWLEDGEMENTS}

Boris Serafimov and Mel Toumazos provided detailed data contributing to the study in their design, development and deployment of the online course. We thank Abrar Alturkistani for editing the manuscript's citations and references. This project was supported by the European Institute of Innovation and Technology - EIT Health Knowledge and Innovation Community.

\section{REFERENCES}

References [Arial, 10-point, left alignment, upper and lower case] should be cited according to the Bibliography and Citation Style https://iated.org/citation_guide

1. Prentice T, editor. Working together for health. Geneva: World Health Organisation; 2006. ISBN:978-92-4-156317-8

2. Clark RC, Mayer RE. e-Learning and the Science of Instruction: Proven Guidelines for Consumers and Designers of Multimedia Learning. 3rd Revised edition edition. San Francisco, CA: John Wiley \& Sons; 2011. ISBN:978-0-470-87430-1

3. Young G, McLaren L, Maden M. Delivering a MOOC for literature searching in health libraries: evaluation of a pilot project. Health Inf Libr J 2017 Dec;34(4):312-318. PMID:29265692

4. Levin HM, McEwan PJ, Belfield CR, Bowden AB, Shand RD. Economic Evaluation in Education: Cost-Effectiveness and Benefit-Cost Analysis. Third edition. Los Angeles: SAGE Publications, Inc; 2017. ISBN:978-1-4833-8180-0

5. Nicklen P, Rivers G, Ooi C, llic D, Reeves S, Walsh K, Maloney S. An Approach for Calculating Student-Centered Value in Education - A Link between Quality, Efficiency, and the Learning Experience in the Health Professions. PloS One 2016;11(9):e0162941. PMID:27632427

6. Downer A, Shapoval A, Vysotska O, Yuryeva I, Bairachna T. US e-learning course adaptation to the Ukrainian context: lessons learned and way forward. BMC Med Educ 2018 Nov 1;18(1):247. PMID:30382853 
7. Yin RK. Case Study Research and Applications: Design and Methods. Sixth edition. Los Angeles: SAGE Publications, Inc; 2018. ISBN:978-1-5063-3616-9

8. Reeves S, Perrier L, Goldman J, Freeth D, Zwarenstein M. Interprofessional education: effects on professional practice and healthcare outcomes (update). Cochrane Database Syst Rev 2013 Mar 28;(3):CD002213. PMID:23543515

9. Kaplan RS. Flexible budgeting in an activity-based costing framework. American Accounting Assn; 1994.

10. Mak YT, Roush ML. Flexible Budgeting and Variance Analysis in an Activity-Based Costing Environment. Account Horiz Q Publ Am Account Assoc 1994;8(2).

11. Mak YT, Roush ML. Managing activity costs with flexible budgets and variance analysis. Account Horiz 1996.

12. Drury C. Management and Cost Accounting. 10th edition edition. Andover, Hampshire, United Kingdom: Cengage Learning EMEA; 2017. ISBN:978-1-4737-4887-3

13. Atun R, Car J, Majeed A, Wheeler E. eLearning for undergraduate health professional education. Al-Shorbaji N, editor. World Health Organ 2015;156.

14. Meinert E, Reeves S, Eerens J, Banks C, Maloney S, Rivers G, llic D, Walsh K, Majeed A, Car J. Exploring the Cost of eLearning within the field of health professions education: key findings from A systematic scoping review. J Med Internet Res 2019;(In review). 